\title{
Nonoperative treatment of insertional Achilles tendinopathy: a systematic review
}

Xiaosong Zhi ${ }^{1+}$, Xinyuan $\mathrm{Liu}^{2+}$, Jing Han ${ }^{1}$, Yang Xiang ${ }^{3}$, Helin Wu${ }^{4}$, Shijun Wei ${ }^{1,4^{*}}$ and Feng $\mathrm{Xu}^{1,4^{*}}$

\begin{abstract}
Background: Insertional Achilles tendinopathy is difficult to manage, and there is no definite consensus on which nonoperative treatment is superior over the others. We aim to provide a clear summary of the best available evidence for nonoperative treatment specific to insertional Achilles tendinopathy.

Methods: Literatures were searched in PubMed, Embase, and Web of Science databases from inception to October 2020. The results were evaluated independently by two reviewers and assessed against the inclusion/exclusion criteria. All included articles were assessed for methodological quality, and study characteristics were extracted.

Results: Twenty-three studies (containing 35 groups) were eligible for the final review. The treatments included eccentric training, extracorporeal shockwave therapy (ESWT), injections, and combined treatment. Visual analog scale (VAS), Victorian Institute of Sport Assessment-Achilles questionnaire, AOFAS, satisfaction rate, and other scales were used to assess the clinical outcome.

Conclusion: Current evidence for nonoperative treatment specific for insertional Achilles tendinopathy favors ESWT or the combined treatment of ESWT plus eccentric exercises.
\end{abstract}

Keywords: Insertional Achilles tendinopathy, Nonoperative treatment, Systematic review

\section{Introduction}

Insertional Achilles tendinopathy is located at the insertion of the Achilles tendon onto the calcaneus, possibly with the formation of bone spurs and calcifications in the tendon proper at the insertion site. Patients complain of pain, stiffness, and sometimes (a solid) swelling. On physical examination, the tendon insertion is painful. A swelling may be visible and a bony spur may be palpable [1]. The incidence of Achilles tendon pain is approximately $6 \%$ in the general population, and $24 \%$ of the people suffering from heel pain were diagnosed as insertional Achilles tendinopathy (IAT) $[2,3]$. The

\footnotetext{
*Correspondence: wsj1974@yeah.net; gkxf79390@sohu.com

'Xiaosong Zhi and Xinyuan Liu contributed equally to this work and should be considered co-first authors.

'Department of Orthopaedics, General Hospital of Central Theater Command (Wuhan General Hospital of Guangzhou Command, previously), NO. 627, Wuluo Road, Wuhan 430030, Hubei Province, P. R. China

Full list of author information is available at the end of the article
}

incidence of IAT increases with age and is significantly higher in patients with metabolic diseases (e.g., diabetes mellitus, hypercholesterolemia, and hypothyroidism) [4]. However, the exact etiology and pathogenesis remain unclear.

Usually, nonoperative treatment, including eccentric exercise, extracorporeal shock wave therapy (ESWT), NSAIDs, orthotics, laser therapy, platelet-rich plasma injections (PRP), corticosteroid injections, and sclerosant injection, are the primary treatment for Achilles tendinopathy and are mostly effective especially in mid-portion/noninsertional Achilles tendinopathy (pathology at 2-6 cm proximal to Achilles insertion). However, it is widely considered that IAT is a distinct clinical entity [5], and nonsurgical interventions in IAT have not shown expectative clinical outcomes as good as the same treatment in midportion Achilles tendinopathy [6]. Furthermore, there is no definite consensus on which nonoperative treatment is superior over the others. So, we performed this systematic 
review to analyze the effectiveness of different currently used nonoperative therapy for IAT.

\section{Method}

This systematic review was carried out following the Preferred Reporting Items for Systematic Reviews and Meta-Analyses (PRISMA) guidelines [7, 8] during the stages of design, analysis, and reporting.

\section{Search strategy}

Literatures were searched in PubMed, Embase, and Web of Science databases from inception to October 2020. The search items were as follows: (insertional OR insertion) AND (tendinopathy OR tendinitis OR tendinosis OR enthesitis or enthesopathy) AND Achilles. Additional potential literatures were obtained by searching the reference list of the identified full-text articles.

\section{Inclusion and exclusion criteria}

An article included should meet all the following criteria: (1) randomized controlled trial (RCT), non-randomized comparative study, prospective cohort, retrospective cohort study, or case series; (2) patients with insertional Achilles tendinopathy were clinically diagnosed with or without imaging confirmation; (3) nonoperative treatment was applied and clearly described; and (4) reporting the outcome regarding pain or function.

A study was excluded if it met one of these criteria: (1) review articles, meta-analysis, case reports, editorial, surgical articles, cadaveric studies, or animal experiments; (2) treatment only on mid-portion or non-insertional tendinopathy; (3) treatment on insertional Achilles tendinopathy but the data could not be extracted separately; and (4) non-English articles.

\section{Study selection and data extraction}

Two independent authors reviewed all studies by reading titles, abstracts, and full-texts according to the inclusion and exclusion criteria mentioned above. The critical information in the final selected studies were independently extracted by two authors. Any discrepancy was resolved by discussing it until a consensus was reached. The extracted data included the last name of the first author, publication year, level of evidence, study design, publication country, sample size, activity level, mean age, duration of symptoms, diagnosis method, interventions, follow-up time, and outcome.

\section{Quality assessment}

All studies were assessed with the level of evidence [9]. The risk of bias of randomized controlled trials (RCTs) was evaluated using the Cochrane bias tool (https:// handbook-5-1.cochrane.org/), which covered six domains: random sequence generation and allocation concealment (selection bias), blinding of participants (performance bias), blinding of outcome assessment (detection bias), incomplete outcome data (attrition bias), selective reporting (reporting bias), and other bias. Each item was categorized as "high", "low," or "unclear." The methodological quality of non-randomized studies was assessed by methodological index for non-randomized studies (MINORS) covering 12 items with a total score of 24 for comparative studies, in which the first 8 items with a total score of 16 for noncomparative studies [10]. Any discrepancy was resolved by discussing or consulting an expert investigator until a consensus was reached.

\section{Statistical analyses}

The data is presented as weighted means and summed percentages. Statistical analyses from the included studies were used in determining statistical significance of the data. $P$ values are extracted from the original studies or calculated from the reported data. STATA version 12.0 (StataCorp LP, College Station, TX, USA) was used for the whole analysis. Statistical significance was set at $P<.05$.

\section{Results}

\section{Literature search}

The search of PubMed, Embase, Web of Science database, and additional search finally yielded 470 records after duplicates were removed. The studies were screened by reviewing abstracts and full-texts according to the inclusion and exclusion criteria, and 23 studies [6, 11-32] (containing 35 groups) were eligible for the final review, including 11 comparative studies (6 RCTs, 5 non-randomized comparative studies) and 12 noncomparative studies. The studies were published from 2003 to 2020. Of those, 3 studies were conducted in Sweden, 4 in the USA, 2 in Germany, 1 in Canada, 1 in Australia, 5 in Italy, 3 in the UK, 2 in China, 1 in Brazil, and 1 in Thailand. The detailed information is shown in Fig. 1 and Table 1. This study followed the PRISMA 2009 checklist as provided in Additional file 1.

\section{Population characteristics}

The available data of numbers of patients (tendons) extracted from the included studies are shown in Table 1. Patients with bilateral symptoms were enrolled in 5 studies. Two studies only reported the number of affected tendons, but the number of patients was not given. The symptom duration time of patients were all above 2 months (not reported in 3 studies). Patients in 5 studies were diagnosed only by clinical examination (CE); in 6 studies by CE and ultrasound (US); in 3 studies by $\mathrm{CE}$ and X-ray; in 2 studies by $\mathrm{CE}$, US, and X-ray; in 2 studies by $\mathrm{CE}, \mathrm{MRI}$, and $\mathrm{X}$-ray; in 1 study by $\mathrm{CE}$, US, and MRI; and in 3 studies by CE, US, MRI, and X- 


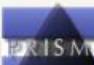

PRISMA 2009 Flow Diagram
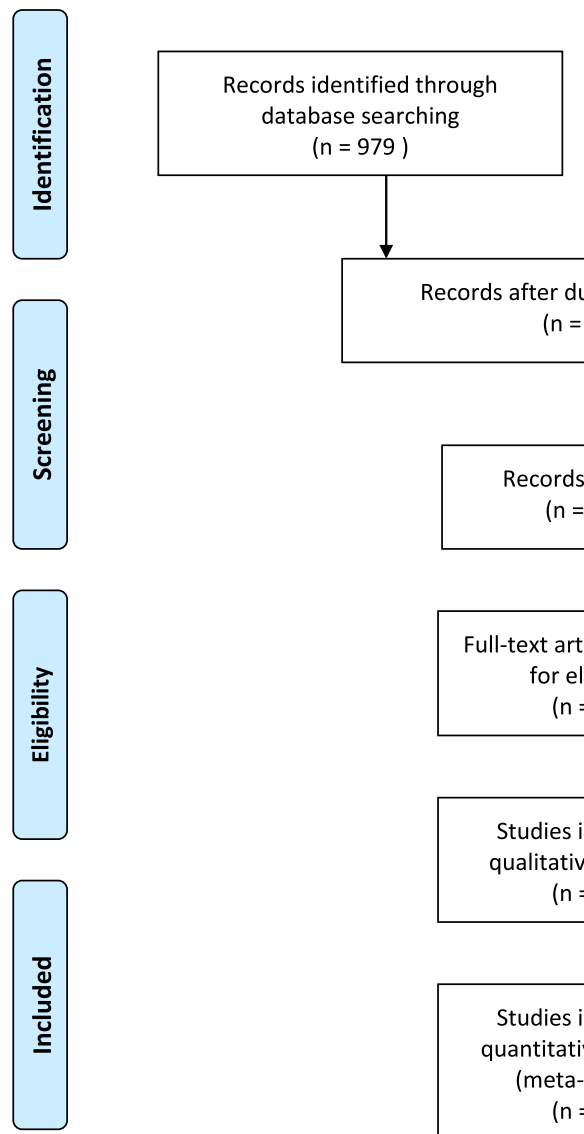

Additional records identified through other sources $(n=979)$ $(n=0)$

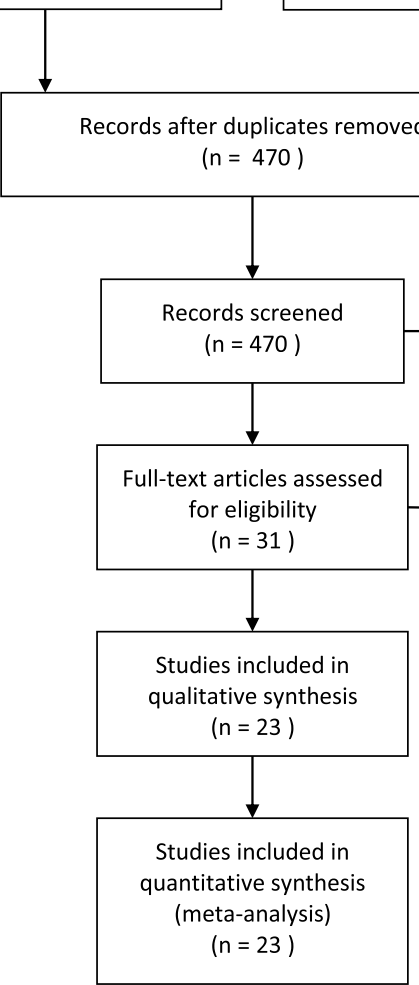

Fig. 1 Flowchart of the literature selection

ray. All patients had follow-ups at least 3 months after specific treatments.

\section{Quality assessment}

The detailed information of quality assessment is shown in Table 2 and Table 3. Seventeen studies were nonrandomized studies, and the methodological quality was assessed by MINORS. Five of them were comparative studies, and the scores ranged from 15 to 22 . The remaining 12 were non-comparative studies, and the scores ranged from 10 to 12 . Six studies were RCTs, and the risk of bias was evaluated by the Cochrane bias tool. For "Other bias" assessment, 4 studies were classed as "high risk" (3 studies pooled both unilateral and bilateral cases, 1 study lacked of randomization on the baseline). The other items of the included RCTs were classed as "low risk" or "unclear."

\section{Eccentric training}

There were 7 groups, a total of 128 patients (144 tendons), receiving eccentric training treatment (Table 4). Of those, 6 groups performed a 12-week daily eccentric training regimen, and 1 group was treated with a 6 -week eccentric stretching regimen. The training protocol also varied between studies: 5 groups required full-range eccentric exercises (heel lower than forefoot), the other 2 groups performed floor-level eccentric training. Two groups failed in previous nonoperative management (including injection of a local anesthetic and/or a corticosteroid, physiotherapy and/or use of orthotics or a heel lift) before eccentric training. One group received combined eccentric training and conventional physical therapy including gastrocnemius, soleus, hamstring stretches, and ice massage on the Achilles tendon twice a day. With regard to the outcome, a 10-point visual analog scale (VAS) or numerical pain scale was reported 
Table 1 Characteristics of included studies and population

\begin{tabular}{|c|c|c|c|c|c|c|c|c|c|c|}
\hline No. & Study & Year & LOE & Study design & Country & $\begin{array}{l}\text { No. of patients } \\
\text { (tendons) }\end{array}$ & Activity level & Age (year) & $\begin{array}{l}\text { Duration of } \\
\text { symptoms } \\
\text { (month) }\end{array}$ & Diagnosis \\
\hline 1 & Fahlström et al. & 2003 & 4 & Prospective & Sweden & $30(31)$ & Recreational & 37.9 & 32 & CE, US, MRI, X-ray \\
\hline 2 & Öhberg et al. & 2003 & 4 & Pilot study & Sweden & $11(11)$ & Mixed & 44 & 29 & CE, US \\
\hline \multirow[t]{3}{*}{3} & Costantino et al. & 2005 & 3 & Retrospective & Italy & Group A 5 (5) & Professional & 32.7 & $\geq 2$ & CE, US \\
\hline & & & & & & Group B 5 (5) & Professional & 32.7 & $\geq 2$ & \\
\hline & & & & & & Group C 5 (5) & Professional & 32.7 & $\geq 2$ & \\
\hline \multirow[t]{2}{*}{4} & Furia et al. & 2006 & 3 & Retrospective & USA & Group A 35 (35) & Mixed & 50 & 19.9 & CE, MRI, X-ray \\
\hline & & & & & & Group B 33 (33) & Mixed & 52.6 & 16.8 & \\
\hline 5 & Knobloch et al. & 2007 & 4 & Prospective & Germany & $10(10)$ & Recreational & $N R$ & $\geq 3$ & CE, US \\
\hline \multirow[t]{2}{*}{6} & Rompe et al. & 2008 & 1 & $\mathrm{RCT}$ & Germany & $25(30)$ & Mixed & 39.2 & 24.8 & CE, US, X-ray \\
\hline & & & & & & $25(31)$ & Mixed & 40.4 & 26.3 & \\
\hline 7 & Jonsson et al. & 2008 & 4 & Pilot study & Sweden & $27(34)$ & Recreational & 53.4 & 26.5 & CE, US \\
\hline 8 & Ryan et al. & 2010 & 4 & Case series & Canada & NR (22) & $N R$ & $N R$ & $\geq 6$ & CE, US \\
\hline 9 & Verrall et al. & 2011 & 4 & Retrospective & Australia & $14(14)$ & Professional & $N R$ & 4.5 & $C E$ \\
\hline 10 & Saxena et al. & 2011 & 2 & Prospective & USA & NR (19) & NR & 54.3 & $N R$ & CE, MRI, X-ray \\
\hline \multirow[t]{2}{*}{11} & Notarnicola et al. & 2012 & 1 & $\mathrm{RCT}$ & Italy & Group A 32 (32) & $N R$ & $N R$ & 6 & CE, US, MRI, X-ray \\
\hline & & & & & & Group B 32 (32) & $N R$ & $N R$ & 6 & \\
\hline \multirow[t]{2}{*}{12} & Notarnicola et al. & 2013 & 2 & $\mathrm{RCT}$ & Italy & Group A 30 (30) & $N R$ & 57.5 & $\geq 6$ & CE, US, MRI, X-ray \\
\hline & & & & & & Group B 30 (30) & $N R$ & 59.5 & $\geq 6$ & \\
\hline \multirow[t]{2}{*}{13} & Kedia et al. & 2014 & 2 & $\mathrm{RCT}$ & USA & Group A 16 (19) & Mixed & 51.7 & 18.5 & $C E$ \\
\hline & & & & & & Group B 20 (20) & Mixed & 55.3 & 18.3 & \\
\hline \multirow[t]{2}{*}{14} & McCormack et al. & 2016 & 2 & $\mathrm{RCT}$ & USA & Group A 6 (6) & $N R$ & 53.3 & 21.9 & CE \\
\hline & & & & & & Group B 6 (6) & $N R$ & 53.9 & 20.8 & \\
\hline 15 & Taylor et al. & 2016 & 4 & Prospective & UK & $12(12)$ & $N R$ & 54 & 42 & CE, US \\
\hline 16 & Pavone et al. & 2016 & 4 & Case series & Italy & $40(40)$ & $N R$ & 41 & $\geq 3$ & $C E, X$-ray \\
\hline \multirow[t]{2}{*}{17} & Wu et al. & 2016 & 3 & Retrospective & China & Group A 37 (37) & $N R$ & 37.6 & $\geq 6$ & CE, X-ray \\
\hline & & & & & & Group B 30 (30) & $N R$ & 35.8 & $\geq 6$ & \\
\hline \multirow[t]{2}{*}{18} & Erroi et al. & 2017 & 3 & Retrospective & Italy & Group A 24 (24) & Mixed & 53.2 & 13.7 & CE, US \\
\hline & & & & & & Group B 21 (21) & Mixed & 47.7 & 14.3 & \\
\hline 19 & Maffulli et al. & 2018 & 4 & Case series & UK & $80(80)$ & NR & 53.4 & $N R$ & $C E$ \\
\hline 20 & Wheeler et al. & 2019 & 4 & Case series & UK & $30(30)$ & NR & 55.4 & 21 & $C E$ \\
\hline 21 & Mansur et al. & 2019 & 3 & Prospective & Brazil & $19(19)$ & $N R$ & 51 & $N R$ & CE, US, X-ray \\
\hline \multirow[t]{2}{*}{22} & Pinitkwamdee et al. & 2020 & 1 & $\mathrm{RCT}$ & Thailand & Group A 16 (22) & Mixed & 61.4 & 7.5 & CE,X-ray \\
\hline & & & & & & Group B 15 (16) & Mixed & 56.5 & 12 & \\
\hline \multirow[t]{2}{*}{23} & Zhang et al. & 2020 & 3 & Retrospective & China & Group A 16 (16) & Sports-active & 31 & $\geq 3$ & CE, US, MRI \\
\hline & & & & & & Group B 17 (17) & Nonsports-active & 37 & $\geq 3$ & \\
\hline
\end{tabular}

Abbreviations: $L O E$ level of evidence, No. number, $R C T$ randomized controlled trial, $N R$ not reported, $C E$ clinical examination, US ultrasound, $M R I$ magnetic resonance imaging

in 7 studies. After combining the results, the weighted mean of declined value of the pain scale was 2.83 . In 2 groups who failed in the previous nonoperative management, the mean declined value was 1.95 versus 3.48 in the other 5 groups. The patient satisfaction after eccentric training was documented in 5 studies. Overall, 47 of 103 (45.6\%) patients thought the outcome was excellent/good, while the others considered it as fair/poor. And the satisfactory rate of 2 groups (failed in previous treatments) was $30.4 \%$ vs. $63.8 \%$ in the other 3 groups. A Victorian Institute of Sport Assessment-Achilles questionnaire (VISA-A) was finished in 2 studies. The mean value increased from 50.6 to 64 . 
Table 2 MINORS of non-randomized studies

\begin{tabular}{lll}
\hline Studies & Study design & MINORS \\
\hline Fahlström et al. 2003 [6] & Non-comparative & 12 \\
Öhberg et al. 2003 [11] & Non-comparative & 11 \\
Costantino et al. 2005 [12] & Comparative & 18 \\
Furia et al. 2006 [13] & Comparative & 20 \\
Knobloch et al. 2007 [14] & Non-comparative & 12 \\
Jonsson et al. 2008 [16] & Non-comparative & 12 \\
Ryan et al. 2010 [17] & Non-comparative & 12 \\
Verrall et al. 2011 [18] & Non-comparative & 10 \\
Saxena et al. 2011 [19] & Non-comparative & 12 \\
Taylor et al. 2016 [24] & Non-comparative & 10 \\
Pavone et al. 2016 [25] & Non-comparative & 12 \\
Wu et al. 2016 [26] & Comparative & 22 \\
Erroi et al. 2017 [27] & Comparative & 18 \\
Maffulli et al. 2018 [28] & Non-comparative & 12 \\
Wheeler et al. 2019 [29] & Non-comparative & 12 \\
Mansur et al. 2019 [30] & Non-comparative & 12 \\
Zhang et al. 2020 [32] & Comparative & 15 \\
\hline
\end{tabular}

\section{Extracorporeal shockwave therapy}

Patients in 12 groups were treated with either exclusively extracorporeal shockwave therapy (ESWT) or ESWT combined with other nonoperative therapy (without eccentric training) (Table 5). Eleven of the 12 groups were applied with low-energy ESWT (shockwave energy < $0.28 \mathrm{~mJ} / \mathrm{mm}^{2}$ ), 1 of them received high-energy ESWT (shockwave energy $>0.6 \mathrm{~mJ} / \mathrm{mm}^{2}$ ) [24]. Besides, 7 of the 12 groups had a failure of previous nonoperative therapy. One group was treated with ESWT and additional arginine supplement. Another group received both ESWT and other conventional treatment but without eccentric training. One group was diagnosed with IAT with a Haglund's deformity. VAS scale was evaluated in 9 of the 12 groups at the final follow-up. The weighted mean of decreased VAS in 8 groups was 4.49 points. The change in the range of VAS in sub-groups showed as 5.10 (high energy) vs. 4.40 (low energy) and 4.15 (failure in previous therapy) vs. 5.12 (no previous therapy). VISA-A was assessed in 7 of the 12 groups, and the mean value increased from 47.5 to 76.2 in combined results. AOFAS was recorded in 2 groups, and the mean value increased from 68.2 to 84.5 . Five groups were evaluated with satisfactory results, and 101 out of 137 (73.7\%) patients were satisfied with the outcome.

\section{ESWT combined with eccentric training}

Five groups received a combined treatment of both ESWT and eccentric training (Table 6). The ESWT in 3 of them applied low-energy shockwave treatments, and the other 2 groups used high-energy shockwave treatments. Three groups had failed in a previous treatment. The VAS scale was evaluated in all 5 patient groups, and the weighted mean of declined value was 4.42 points. VISA-A was assessed in 3 groups, and the mean value increased from 47.9 to 69.4. AOFAS was assessed in 3 groups, and it changed from 68.3 at baseline to 83.4 at the final follow-up. Satisfactory results were recorded in 4 groups, and the total satisfaction rate was $74.3 \%$ (84/113).

\section{Other nonoperative treatments}

Other nonoperative treatments were summarized in Table 7. In a pilot study, 11 tendons were injected with sclerosing agent polidocanol, and the VAS scale decreased from 8.3 to 2.8 during 8 months follow-up [11]. Costantino et al. compared three therapies (cryoultrasound therapy, laser therapy $\mathrm{CO} 2$, and t.e.ca.r. therapy) in athletes affected by insertional tendonitis and found that every patient benefited from all the treatments [12]. In a prospective case series study, 22 tendons were injected with $25 \%$ dextrose-lidocaine. After 28.6 months, the VAS decreased from 7.0 to 1.8 [17]. In a prospective clinical trial, cold air and high-energy laser therapy (CHELT) gave quicker and better pain relief. It also gave the patient a full functional recovery and greater satisfaction [21]. Furia, Kedia and Pinitkwamdee showed that conventional intervention (without ECC) decreased the pain and improved the function [13, 22, 31]. McCormack et al. showed that soft tissue treatment (Astym) plus

Table 3 Summary of risk of bias of randomized studies

\begin{tabular}{|c|c|c|c|c|c|c|c|}
\hline Studies & $\begin{array}{l}\text { Random sequence } \\
\text { generation } \\
\text { (selection bias) }\end{array}$ & $\begin{array}{l}\text { Allocation } \\
\text { concealment } \\
\text { (selection bias) }\end{array}$ & $\begin{array}{l}\text { Blinding of } \\
\text { participants } \\
\text { (performance } \\
\text { bias) }\end{array}$ & $\begin{array}{l}\text { Blinding of } \\
\text { outcome } \\
\text { assessment } \\
\text { (detection bias) }\end{array}$ & $\begin{array}{l}\text { Incomplete } \\
\text { outcome } \\
\text { (attrition bias) }\end{array}$ & $\begin{array}{l}\text { Selective } \\
\text { reporting } \\
\text { (reporting bias) }\end{array}$ & $\begin{array}{l}\text { Other } \\
\text { bias }\end{array}$ \\
\hline Rompe et al. 2008 [15] & Low & Low & Unclear & Low & Low & Unclear & High \\
\hline Notarnicola et al. 2012 [20] & Low & Unclear & Low & Low & Low & Unclear & High \\
\hline Notarnicola et al. 2013 & Unclear & Unclear & Low & Unclear & Low & Unclear & Unclear \\
\hline Kedia et al. 2014 [22] & Low & Low & Unclear & Low & Low & Unclear & High \\
\hline McCormack et al. 2016 [23] & Low & Low & Unclear & Unclear & Low & Unclear & Unclear \\
\hline Pinitkwamdee et al. 2020 [31] & Low & Low & Low & Low & Low & Unclear & High \\
\hline
\end{tabular}


Table 4 Summary of ECC training and outcomes in identified studies

\begin{tabular}{|c|c|c|c|c|c|c|c|c|}
\hline Study & Year & Intervention & LOE & $\begin{array}{l}\text { Previous } \\
\text { treatment }\end{array}$ & $\begin{array}{l}\text { Follow-up } \\
\text { (month) }\end{array}$ & $\begin{array}{l}\text { Evaluation and } \\
\text { outcome }\end{array}$ & Significance & Overall \\
\hline \multirow[t]{2}{*}{ Fahlström } & \multirow[t]{2}{*}{2003} & \multirow[t]{2}{*}{ ECC training (full range): 12 weeks } & \multirow[t]{2}{*}{4} & \multirow[t]{2}{*}{ Failed } & \multirow[t]{2}{*}{3} & VAS: 7.6 to 5.5 & \multirow[t]{2}{*}{ n.s. } & \multirow{17}{*}{$\begin{array}{l}\text { VAS: }-2.83 \\
\text { VISA-A: } 50.6 \text { to } 64 \\
\text { Satisfaction: } 45.6 \% \\
(47 / 103)\end{array}$} \\
\hline & & & & & & Satisfaction: $32.2 \%$ & & \\
\hline Knobloch & 2007 & ECC training (full range): 12 weeks & 4 & None & 3 & VAS: 6 to 3.2 & * & \\
\hline \multirow[t]{3}{*}{ Rompe } & \multirow[t]{3}{*}{2008} & \multirow[t]{3}{*}{ ECC training (full range): 12 weeks } & \multirow[t]{3}{*}{1} & \multirow[t]{3}{*}{ Failed } & \multirow[t]{3}{*}{4} & VAS: 6.8 to 5.0 & * & \\
\hline & & & & & & VISA-A: 52.7 to 63.4 & * & \\
\hline & & & & & & Satisfaction: $28 \%$ & & \\
\hline \multirow[t]{2}{*}{ Jonsson } & \multirow[t]{2}{*}{2008} & \multirow[t]{2}{*}{ ECC training (floor level): 12 weeks } & \multirow[t]{2}{*}{4} & \multirow[t]{2}{*}{ NR } & \multirow[t]{2}{*}{4} & VAS: 7.2 to 3.3 & \multirow[t]{2}{*}{ * } & \\
\hline & & & & & & Satisfaction: $66.7 \%$ & & \\
\hline \multirow[t]{2}{*}{ Verrall } & \multirow[t]{2}{*}{2011} & \multirow[t]{2}{*}{ ECC training (full range): 6 weeks } & \multirow[t]{2}{*}{4} & \multirow[t]{2}{*}{ NR } & \multirow[t]{2}{*}{3} & VAS: 7.3 to 3.0 & \multirow[t]{2}{*}{ * } & \\
\hline & & & & & & Satisfaction: $50 \%$ & & \\
\hline \multirow[t]{4}{*}{ Kedia } & \multirow[t]{4}{*}{2014} & \multirow[t]{4}{*}{$\begin{array}{l}\text { ECC (full range)+strengthening } \\
\text { training: } 12 \text { weeks }\end{array}$} & \multirow[t]{4}{*}{2} & \multirow[t]{4}{*}{ NR } & \multirow[t]{4}{*}{3} & VAS: -2.19 & * & \\
\hline & & & & & & SF-36 (bodily pain): 16.22 & * & \\
\hline & & & & & & SF-36: 9.78 & n.s. & \\
\hline & & & & & & FAOQ: -0.73 & * & \\
\hline \multirow[t]{3}{*}{ McCormack } & \multirow[t]{3}{*}{2016} & ECC training (floor level): 12 weeks & 2 & None & 13 & VAS: 5.4 to 1 & * & \\
\hline & & & & & & VISA-A: 40.2 to 67 & * & \\
\hline & & & & & & Satisfaction: 83.3\% & & \\
\hline
\end{tabular}

n.s. no significance

${ }^{*} P<0.05$

eccentric exercise improved the function during both short- and long-term follow-up periods [23]. Erroi et al. showed that PRP plus exercise gave a significant improvement of VISA-A and VAS scores at all time-points [27].

\section{Comparative studies}

There were 11 comparative studies (5 retrospective cohort studies, 6 RCTs) with regard to different interventions (Table 8). Costantino et al. compared three therapies (cryoultrasound therapy, laser therapy $\mathrm{CO} 2$, and t.e.ca.r. therapy) in athletes affected by insertional tendonitis and found that cryoultrasound showed significant advantages over the other two, but there was no significant difference between laser therapy $\mathrm{CO} 2$ and t.e.ca.r. therapy [12]. Furia et al. showed that high-energy ESWT was more effective than conventional nonoperative treatment (rest, medication, activity modification, stretching exercise, and heel lift orthosis) whenever VAS or satisfaction rates were evaluated [13]. In a RCT from Rompe et al., eccentric loading showed inferior results to low-energy ESWT as applied in patients with chronic recalcitrant insertional tendinopathy at 4 months of follow-up [15]. Notarnicola et al. demonstrated that ESWT with additional dietary supplement containing arginine, Vinitrox ${ }^{\mathrm{Tm}}$, collagen, methyl-sulfonylmethane, vitamin $\mathrm{C}$, and bromelain significantly improved the therapeutic response when compared to ESWT with placebo [20]. In another RCT from Notarnicola et al., highenergy laser therapy gave quicker pain relief and gave the patients greater satisfaction than low-energy ESWT [21]. McCormack et al. found that soft tissue treatment (Astym) plus eccentric training was more effective than eccentric exercise alone at improving function (VISA-A) during both short- and long-term follow-up periods [23]. However, Kedia et al. found that conventional physical therapy consisting of gastrocnemius, soleus and hamstring stretches, ice, and use of heel lifts and night splints with or without eccentric training were both effective and showed no significant difference [22]. Besides, no difference was found at 24 weeks between the standard nonoperative treatment combined with low-energy ESWT and low-energy ESWT alone for chronic insertional Achilles tendinopathy, especially in elderly patients [31]. Wu et al. found that ESWT resulted in greater clinical outcomes in patients without Haglund's deformity compared with patients with Haglund's deformity [26]. Erroi et al. demonstrated that both ESWT and PRP therapy were effective and safe, and there were no significant differences between two groups in VAS, VISA-A, or satisfaction rate [27]. Zhang et al. showed that patients with IAT who had greater sports activity levels had better therapeutic responses to ESWT than nonsports-active patients after a 5-year follow-up [32].

\section{Discussion}

\section{Eccentric exercises}

Eccentric exercises are traditional and one of the most recommended nonoperative treatments for Achilles 
Table 5 Summary of ESWT and outcomes in identified studies

\begin{tabular}{|c|c|c|c|c|c|c|c|c|}
\hline Study & Year & Intervention & LOE & $\begin{array}{l}\text { Previous } \\
\text { treatment }\end{array}$ & $\begin{array}{l}\begin{array}{l}\text { Follow-up } \\
\text { (month) }\end{array} \\
\end{array}$ & Evaluation and outcome & Significance & Overall \\
\hline \multirow[t]{2}{*}{ Furia } & \multirow[t]{2}{*}{2006} & \multirow[t]{2}{*}{ ESWT (high energy) } & \multirow[t]{2}{*}{3} & \multirow[t]{2}{*}{ Failed } & \multirow[t]{2}{*}{12} & VAS: 7.9 to 2.8 & \multirow[t]{2}{*}{ * } & \multirow{5}{*}{$\begin{array}{l}\text { VAS: }-4.49 \\
\text { VISA-A: } 47.5 \text { to } 76.2 \\
\text { Satisfaction: } 73.7 \% \\
\text { (101/137) } \\
\text { AOFAS: } 68.2 \text { to } 84.5\end{array}$} \\
\hline & & & & & & Satisfaction: $82.9 \%$ & & \\
\hline \multirow[t]{3}{*}{ Rompe } & \multirow[t]{3}{*}{2008} & \multirow[t]{3}{*}{ ESWT (low energy) } & \multirow[t]{3}{*}{1} & \multirow[t]{3}{*}{ Failed } & \multirow[t]{3}{*}{12} & VAS: 7.0 to 3.0 & * & \\
\hline & & & & & & VISA-A: 53.2 to 79.4 & \multirow[t]{2}{*}{ * } & \\
\hline & & & & & & Satisfaction: $64 \%$ & & \\
\hline Saxena & 2011 & ESWT (low energy) & 2 & None & $12-24$ & Satisfaction: $82.4 \%$ & & \\
\hline \multirow[t]{4}{*}{ Notarnicola } & \multirow[t]{4}{*}{2012} & \multirow[t]{4}{*}{ ESWT (low energy)+dietary } & \multirow[t]{4}{*}{1} & \multirow[t]{4}{*}{ None } & \multirow[t]{4}{*}{6} & VAS: 7.1 to 2.0 & * & \\
\hline & & & & & & AOFAS: 70.6 to 92.4 & * & \\
\hline & & & & & & Oximetry: $75.4 \%$ to $60.2 \%$ & * & \\
\hline & & & & & & Satisfaction: $93.8 \%$ & & \\
\hline \multirow[t]{4}{*}{ Notarnicola } & \multirow[t]{4}{*}{2012} & \multirow[t]{4}{*}{ ESWT (low energy)+placebo } & \multirow[t]{4}{*}{1} & \multirow[t]{4}{*}{ None } & 6 & VAS: 7.1 to 2.9 & * & \\
\hline & & & & & & AOFAS: 65.8 to 76.5 & * & \\
\hline & & & & & & Oximetry: $73.0 \%$ to $66.0 \%$ & * & \\
\hline & & & & & & Satisfaction: $38.5 \%$ & & \\
\hline Taylor & 2016 & ESWT (low energy) & 4 & Failed & 24 & VAS: 6.7 to 2.8 & * & \\
\hline & & & & & & VISA-A: 43 to 70 & * & \\
\hline Wu & 2016 & ESWT (low energy) & 3 & Failed & 14.5 & VISA-A: 49.6 to 83.9 & * & \\
\hline & & & & & & Likert: 3.92 to 1.57 & * & \\
\hline Wu & 2016 & $\begin{array}{l}\text { ESWT (low energy) (with } \\
\text { Haglund's deformity) }\end{array}$ & 3 & Failed & 15.3 & VISA-A: 48.7 to 67.8 & * & \\
\hline & & & & & & Likert: 4.0 to 2.37 & * & \\
\hline Maffulli & 2018 & ESWT (low energy) & 4 & Failed & 24 & VAS: 5.9 to 1.8 & * & \\
\hline & & & & & & VISA-A: 42.0 to 72.3 & * & \\
\hline & & & & & & EQ-5D (anxiety): 1.36 to 1.1 & n.s. & \\
\hline & & & & & & EQ-5D (mobility): 1.71 to 1.35 & * & \\
\hline & & & & & & EQ-5D (pain): 2.0 to 1.52 & * & \\
\hline & & & & & & EQ-5D (usual activity): 1.8 to 1.35 & * & \\
\hline & & & & & & EQ-5D (self-care): 1.11 to 1.0 & n.s. & \\
\hline & & & & & & EQ-5D (thermometer): 65.3 to 77.3 & n.s. & \\
\hline Pinitkwamdee & 2020 & $\begin{array}{l}\text { ESWT (low energy)+conservative } \\
\text { (without ECC) }\end{array}$ & 1 & Failed & 6 & VAS: 6.0 to 2.8 & * & \\
\hline & & & & & & VAS-FA: 64.8 to 77.2 & n.s. & \\
\hline & & & & & & Pain: 54.4 to 70.1 & n.s. & \\
\hline & & & & & & Function: 60.1 to 76.0 & n.s. & \\
\hline & & & & & & Other complaints: 80.0 to 85.8 & n.s. & \\
\hline Zhang & 2020 & ESWT (low energy) & 3 & None & 60 & VAS: 7.0 to 0.3 & * & \\
\hline & & & & & & VISA-A: 56 to 90 & * & \\
\hline Zhang & 2020 & ESWT (low energy) & 3 & None & 60 & VAS:7.0 to 1.6 & * & \\
\hline & & & & & & VISA-A: 51 to 78 & * & \\
\hline
\end{tabular}

tendinopathy [33-35], especially for mid-portion/noninsertional Achilles tendinopathy [34, 36]. Eccentric exercises were reported to decrease local pain by strengthening the calf muscle, lengthening of the myotendinous unit, and decreasing neovascularization in the region. The combined results of 6 groups in this systematic review showed that the weighted mean of VAS scale had a decline of 2.83 points, which might suggest that eccentric training was an effective treatment for IAT. However, there were no RCTs to compare the eccentric training with sham control to make a firm conclusion. Besides, a prospective cohort study from Fahlström et al. found that eccentric training resulted in only $32 \%$ satisfaction in patients with IAT, while the rate $(89 \%)$ was 
Table 6 Summary of ESWT combined with ECC and outcomes in identified studies

\begin{tabular}{|c|c|c|c|c|c|c|c|c|}
\hline Study & Year & Intervention & LOE & $\begin{array}{l}\text { Previous } \\
\text { treatment }\end{array}$ & $\begin{array}{l}\text { Follow-up } \\
\text { (month) }\end{array}$ & $\begin{array}{l}\text { Evaluation and } \\
\text { outcome }\end{array}$ & Significance & Overall \\
\hline \multirow[t]{2}{*}{ Notarnicola } & 2013 & ESWT (low energy)+ECC & 2 & None & 6 & VAS: 7.0 to 3.3 & * & \\
\hline & & & & & & AOFAS: 67.0 to 76.9 & * & $\begin{array}{l}47.9 \text { to } 69.4 \\
\text { Satisfaction: } 74.3 \%(84 / 113)\end{array}$ \\
\hline \multirow[t]{3}{*}{ Pavone } & 2016 & ESWT (low energy)+ECC & 4 & Failed & 12 & VAS: 7.6 to 1.9 & * & AOFAS: 68.3 to 93.4 \\
\hline & & & & & & AOFAS: 71.4 to 91.3 & * & \\
\hline & & & & & & Satisfaction: $65 \%$ & & \\
\hline \multirow[t]{3}{*}{ Erroi } & 2017 & $\begin{array}{l}\text { ESWT (low energy)+exercise } \\
\text { (include ECC) }\end{array}$ & 3 & Failed & 6 & VAS: 6.4 to 1.5 & * & \\
\hline & & & & & & VISA-A: 50.6 to 86.5 & * & \\
\hline & & & & & & Satisfaction: $87.5 \%$ & & \\
\hline \multirow[t]{10}{*}{ Wheeler } & 2019 & $\begin{array}{l}\text { ESWT (high energy)+exercise } \\
\text { (include ECC) }\end{array}$ & 4 & NR & 6 & VAS: 6.5 to 2.0 & * & \\
\hline & & & & & & VISA-A: 28 to 60 & * & \\
\hline & & & & & & Satisfaction: $80 \%$ & & \\
\hline & & & & & & $\begin{array}{l}\text { Self-reported worst pain: } \\
8.0 \text { to } 5.0\end{array}$ & * & \\
\hline & & & & & & $\begin{array}{l}\text { Self-reported stiffness: } \\
6.0 \text { to } 3.0\end{array}$ & * & \\
\hline & & & & & & FAAM-ADL: $57 \%$ to $85 \%$ & * & \\
\hline & & & & & & pD: 15 to 9.5 & * & \\
\hline & & & & & & $\begin{array}{l}\text { EQ-5D(health): } 70 \% \\
\text { to } 85 \%\end{array}$ & n.s. & \\
\hline & & & & & & HADS (anxiety): 5.0 to 3.0 & n.s. & \\
\hline & & & & & & $\begin{array}{l}\text { HADS (depression): } 3.0 \\
\text { to } 2.0\end{array}$ & n.s. & \\
\hline \multirow[t]{4}{*}{ Mansur } & 2019 & ESWT (high energy)+ECC & 3 & NR & 6 & VAS: 5.3 to 3.2 & * & \\
\hline & & & & & & VISA-A: 49.1 to 62.6 & * & \\
\hline & & & & & & AOFAS: 63.6 to 77.2 & * & \\
\hline & & & & & & Satisfaction: 68.4\% & & \\
\hline
\end{tabular}

much higher in patients with mid-portion Achilles tendinopathy [6]. In a RCT, conventional physical therapy with or without eccentric training exerted equal effects for IAT [22]. So, whether eccentric exercises are suitable for IAT is still open for debate. Because of the limited and conflicting evidence, eccentric exercise was given a Grade I recommendation according to the Grades of Recommendation [2]. Further RCTs of large samples comparing eccentric exercises and sham control (wait and see) groups are needed. Moreover, maximum load, speed of contraction, and frequency of sessions should also be studied and optimized.

\section{Extracorporeal shock wave therapy}

Recently, high- and low-energy ESWT have been used for the treatment of Achilles tendinopathy and have shown good outcomes [13, 28, 31, 37]. The weighted mean of decreased VAS in 9 of 12 groups was 4.49 points (larger than that of eccentric exercises) at the final follow-up. The overall satisfaction rate of ESWT of the included studies is $73.7 \%$, much higher than that of eccentric training (45.6\%). Among the total 11 groups, patients from 6 groups, who were enrolled in these studies to receive ESWT, had unsatisfactory results from other nonoperative treatments before. Besides, in a RCT reported by Rompe et al., low-energy ESWT showed superiority over eccentric training in patients with chronic recalcitrant tendinopathy at the 4-month follow-up [15]. In a retrospective comparative study, high-energy ESWT was more effective than traditional nonoperative methods after the 12-month follow-up [13]. However, another RCT indicated that low-energy ESWT had no significant benefit for IAT at the 24 weeks follow-up, especially in the elderly [31]. But the sample size (16/15) was small, and the younger patients were not fully evaluated. One big problem of ESWT is the high amount of pain during the 
Table 7 Summary of other treatment and outcomes in identified studies

\begin{tabular}{|c|c|c|c|c|c|c|c|}
\hline Study & Year & Intervention & LOE & $\begin{array}{l}\text { Previous } \\
\text { treatment }\end{array}$ & $\begin{array}{l}\text { Follow-up } \\
\text { (month) }\end{array}$ & Evaluation and outcome & Significance \\
\hline \multirow[t]{2}{*}{ Öhberg } & 2003 & Sclerosing therapy & 4 & Failed & 8 & VAS: 8.3 to 2.8 & * \\
\hline & & & & & & Satisfaction: $72.7 \%$ & \\
\hline Costantino & 2005 & Cryoultrasound therapy & 3 & NR & 8 & VAS: 9 to 1.8 & * \\
\hline Costantino & 2005 & Laser CO2 & 3 & NR & 8 & VAS: 9 to 2.8 & * \\
\hline Costantino & 2005 & t.e.ca.r. therapy & 3 & NR & 8 & VAS: 9 to 2.0 & * \\
\hline \multirow[t]{2}{*}{ Furia } & 2006 & Conservative (without ECC) & 3 & Failed & 12 & VAS: 8.6 to 7.0 & n.s. \\
\hline & & & & & & Satisfaction: $39.4 \%$ & \\
\hline \multirow[t]{3}{*}{ Ryan } & 2010 & Dextrose injections & 4 & Failed & 28.6 & VAS at rest: 3.3 to 0.3 & * \\
\hline & & & & & & VAS with activity: 5.1 to 1.0 & * \\
\hline & & & & & & VAS during sports: 7.0 to 1.8 & * \\
\hline \multirow[t]{2}{*}{ Notarnicola } & 2013 & CHELT+ECC & 2 & None & 6 & VAS: 7.0 to 1.7 & * \\
\hline & & & & & & AOFAS: 62.5 to 83.0 & * \\
\hline \multirow[t]{4}{*}{ Kedia } & 2014 & Strengthening training: 12 weeks & 2 & NR & 3 & VAS: -2.08 & * \\
\hline & & & & & & SF-36(bodily pain): 16.4 & * \\
\hline & & & & & & SF-36: 10.27 & * \\
\hline & & & & & & FAOQ: -0.758 & * \\
\hline \multirow[t]{3}{*}{ McCormack } & 2016 & ECC training+Astym: 12 weeks & 2 & None & 13 & VISA-A: 36.6 to 90.7 & * \\
\hline & & & & & & NPRS: 4.6 to 0.67 & * \\
\hline & & & & & & Satisfaction: $100 \%$ & \\
\hline \multirow[t]{3}{*}{ Erroi } & 2017 & PRP+exercise (include ECC) & 3 & Failed & 6 & VAS: 5.9 to 2.6 & * \\
\hline & & & & & & VISA-A: 52.8 to 82.0 & * \\
\hline & & & & & & Satisfaction: $71.4 \%$ & \\
\hline \multirow[t]{5}{*}{ Pinitkwamdee } & 2020 & Conservative (without ECC) & 1 & Failed & 6 & VAS: 5.2 to 2.0 & * \\
\hline & & & & & & VAS-FA: 65.3 to 82.7 & n.s. \\
\hline & & & & & & Pain: 47.3 to 77.8 & * \\
\hline & & & & & & Function: 66.6 to 82.5 & n.s. \\
\hline & & & & & & Other complaints: 83.9 to 87.9 & n.s. \\
\hline
\end{tabular}

n.s. no significance

${ }^{*} P<0.05$

treatment process. Whether local anesthesia field block should be used and whether anesthesia would affect the outcome remain open for debate. Overall, ESWT is widely used and supported now and has a Grade B recommendation. Further RCTs with a large sample size are needed to verify the effectiveness more accurately.

\section{Injection therapy}

The current therapy of medicinal injections for treating Achilles tendinopathy included sclerosing therapy, hyperosmolar dextrose injections, corticosteroid injections, and platelet-rich plasma (PRP) injections. However, studies with high-quality evidence are rare, especially for insertional form of Achilles tendinopathy. It was considered that the pain was due to the neovascularization outside and inside the affected tendon [38] and could be alleviated in most patients if the neovessels were destroyed by injections of a sclerosing agent [39]. In a pilot study in 2003, the injections of sclerosing agent polidocanol against the local neovessels relieved the pain in 8 out of $11 \mathrm{pa}-$ tients with IAT at the 8-month follow-up [11]. Dextrose, as a kind of prolotherapy, is considered to elicit a proliferant cellular response by inducing inflammation, subsequent growth factor production leading to increased fibroblast proliferation (either locally or systemic) and increased production of extracellular matrix materials [40]. In a retrospective case series report, dextrose injections reduced pain from either the insertion or mid-portion Achilles tendinopathy at the 28.6 months follow-up [17]. Platelet-rich plasma (PRP) injections are a regenerative treatment for Achilles tendinopathy, and its mechanism in vivo is still unclear. Up to date, there was only one study reporting PRP injections in treatment of specific IAT. In this retrospective study, a combination of PRP 
Table 8 Summary of comparative studies

\begin{tabular}{|c|c|c|c|c|c|c|c|}
\hline Study & Year & Intervention & LOE & $\begin{array}{l}\text { Previous } \\
\text { treatment }\end{array}$ & $\begin{array}{l}\text { Follow-up } \\
\text { (month) }\end{array}$ & Evaluation and outcome & Significance \\
\hline Costantino & 2005 & $\begin{array}{l}\text { Cryoultrasound therapy vs. laser } \mathrm{CO} 2 \text { vs. t.e.ca.r. } \\
\text { therapy }\end{array}$ & 3 & NR & 8 & VAS: 1.8 vs. 2.8 vs. 2.0 & n.s. \\
\hline \multirow[t]{2}{*}{ Furia } & 2006 & ESWT (high energy) vs. conservative (without ECC) & 3 & Failed & 12 & VAS: 2.8 vs. 7.0 & * \\
\hline & & & & & & Satisfaction: $82.9 \%$ vs. $39.4 \%$ & * \\
\hline \multirow[t]{3}{*}{ Rompe } & 2008 & ESWT (low energy) vs. ECC training (full range) & 1 & Failed & 12 & VAS: 3.0 vs. 5.0 & * \\
\hline & & & & & & VISA-A: 79.4 vs. 63.4 & * \\
\hline & & & & & & Satisfaction: $64 \%$ vs. $28 \%$ & * \\
\hline \multirow[t]{4}{*}{ Notarnicola } & 2012 & $\begin{array}{l}\text { ESWT (low energy)+dietary vs. ESWT (low } \\
\text { energy)+placebo }\end{array}$ & 1 & NR & 6 & VAS: 2.0 vs. 2.9 & n.s. \\
\hline & & & & & & AOFAS: 92.4 vs. 76.5 & * \\
\hline & & & & & & Oximetry: $60.2 \%$ vs. $66.0 \%$ & * \\
\hline & & & & & & Satisfaction: $93.8 \%$ vs. $38.5 \%$ & * \\
\hline \multirow[t]{2}{*}{ Notarnicola } & 2013 & CHELT+ECC vs. ESWT (low energy)+ECC & 2 & None & 6 & VAS: 1.7 vs. 3.3 & * \\
\hline & & & & & & AOFAS: 83.0 vs. 76.9 & n.s. \\
\hline \multirow[t]{4}{*}{ Kedia } & 2014 & $\begin{array}{l}\text { ECC (full range)+strengthening training vs. } \\
\text { strengthening training }\end{array}$ & 2 & NR & 3 & VAS: -2.19 vs. -2.08 & n.s. \\
\hline & & & & & & $\begin{array}{l}\text { SF-36 (bodily pain): } 16.22 \\
\text { vs. } 16.4\end{array}$ & n.s. \\
\hline & & & & & & SF-36: 9.78 vs. 10.27 & n.s. \\
\hline & & & & & & FAOQ: -0.73 vs. -0.758 & n.s. \\
\hline \multirow[t]{3}{*}{ McCormack } & 2016 & ECC training+Astym vs. ECC training & 2 & None & 3 & VISA-A: 67.0 vs. 90.7 & * \\
\hline & & & & & & NPRS: 1.0 vs. 0.67 & n.s. \\
\hline & & & & & & Satisfaction: $83.3 \%$ vs. $100 \%$ & n.s. \\
\hline \multirow[t]{2}{*}{ Wu } & 2016 & $\begin{array}{l}\text { ESWT (low energy) vs. ESWT (low energy) } \\
\text { (with Haglund's deformity) }\end{array}$ & 3 & Failed & 14.5 & VISA-A: 83.9 vs. 67.8 & * \\
\hline & & & & & & Likert: 1.57 vs. 2.37 & n.s. \\
\hline \multirow[t]{3}{*}{ Erroi } & 2017 & $\begin{array}{l}\text { ESWT (low energy)+exercise (include ECC) } \\
\text { vs. PRP+exercise (include ECC) }\end{array}$ & 3 & Failed & 6 & VAS: 1.5 vs. 2.6 & n.s. \\
\hline & & & & & & VISA-A: 86.5 vs. 82.0 & n.s. \\
\hline & & & & & & Satisfaction: $87.5 \%$ vs. $71.4 \%$ & n.s. \\
\hline \multirow[t]{5}{*}{ Pinitkwamdee } & 2020 & $\begin{array}{l}\text { ESWT (low energy)+conservative } \\
\text { (without ECC) vs. conservative (without ECC) }\end{array}$ & 1 & Failed & 6 & VAS: 2.8 Vs. 2.0 & n.s. \\
\hline & & & & & & VAS-FA: 77.2 vs. 82.7 & n.s. \\
\hline & & & & & & Pain: 70.1 vs. 77.8 & n.s. \\
\hline & & & & & & Function: 76.0 vs. 82.5 & n.s. \\
\hline & & & & & & $\begin{array}{l}\text { Other complaints: } 85.8 \\
\text { vs. } 87.9\end{array}$ & n.s. \\
\hline \multirow[t]{2}{*}{ Zhang } & 2020 & $\begin{array}{l}\text { ESWT (low energy) (sports-active) vs. } \\
\text { ESWT (low energy) (nonsports-active) }\end{array}$ & 3 & None & 60 & VAS: 0.3 to 1.6 & * \\
\hline & & & & & & VISA-A: 90 to 78 & * \\
\hline
\end{tabular}

injections and eccentric exercises was equally effective to combining treatment of ESWT and eccentric training after the 6-month follow-up [27]. Corticosteroid injections have largely fallen out of clinical practice for tendinopathy treatment for the risk of tendon degeneration and tear, and no studies were found applying corticosteroid injection for IAT [41]. Overall, studies regarding various injection therapy for IAT are rare and more evidence are required (Grade I recommendation).

\section{Combination treatment}

IAT is considered to be more refractory than midportion AT, so more trials focus on a combination treatment. In this review, 5 groups were treated with a 
combination of ESWT and eccentric exercises, which were two of the most widely used nonoperative therapies. The weighted mean of declined VAS value was 4.42 points. The total satisfaction rate in 4 groups was $74.3 \%$. These results were similar to those of cases that received single ESWT (73.7\%), but much higher than those of eccentric exercises alone (45.6\%). However, RCTs of direct comparison between the combination and either treatment were lacking, and the superiority of this combination treatment could not be confirmed. Other combination treatments, including Notarnicola et al. (high-energy laser therapy and eccentric exercises) [21], McCormack et al. (soft tissue treatment and eccentric exercise) [23] and Erroi et al. (PRP and home exercises) [27], were all suggested to be effective, but they were all reported by individual study and lacked generalized evidence. In summary, the combination treatment (ESWT and eccentric exercises) for IAT has a Grade B recommendation, and other combination treatments have a Grade I recommendation.

\section{Limitations}

One of the main limitations of this review is the low level of evidence and risk of bias of the included studies. Only 6 studies were RCTs. For many studies, the outcome of treatment is evaluated by a patient-based selfcomparison (pre- vs. post- therapy), and a sham/control (wait and see) group is needed to reflect the effectiveness authentically and accurately. Secondly, the terminology of Achilles tendon pathology varies among studies, so some studies may be excluded during the process of literature screening according to our strict inclusion criteria. Thirdly, for some studies, the diagnosis is based on clinical findings alone without imaging confirmation, which may enlarge the scope of included cases or add the risk of bias.

\section{Conclusion}

IAT is regarded as a distinct clinical entity which is often accompanied with metabolic diseases and is difficult to manage, and the treatment and prognosis of IAT are not totally the same to those of mid-portion/non-insertional Achilles tendinopathy. Although more evidence is in support of eccentric exercises than the other interventions for mid-portion/non-insertional Achilles tendinopathy, eccentric exercises did not result in a high satisfaction rate for IAT. Current evidence for nonoperative treatment favors ESWT or the combined treatment of ESWT plus eccentric exercises. Evidence in support of other therapies (including sclerosing therapy, dextrose injections, strengthening training, PRP, soft tissue treatment) are lacking, and more investigation with high level of evidence is needed.

\section{Supplementary Information}

The online version contains supplementary material available at https://doi. org/10.1186/s13018-021-02370-0.

Additional file 1. PRISMA 2009 checklist.

\section{Acknowledgements}

We would like to express gratitude to John Valerius, an English native speaker, for taking the time to review and revise our manuscript.

\section{Authors' contributions}

$X Z$ and SW designed the study. XZ and XL performed database searches. XZ and $Y X$ reviewed the studies. SW and FX resolved disagreements during the review process. HW generated the synthesis of the results. $X Z, X L, Y X$, and $J H$ drafted the manuscript. SW and FX edited the manuscript. The authors read and approved the final manuscript.

\section{Funding}

This research paper was supported, in part, by the Natural Science Foundation of Hubei Province (2017CFB568)

\section{Availability of data and materials}

The datasets used and/or analyzed during the current study are available from the corresponding author on reasonable request.

\section{Declarations}

Competing interest

The authors declare that they have no competing interest.

Ethics approval and consent to participate

Not applicable.

Consent for publication

Not applicable.

\section{Author details}

${ }^{1}$ Department of Orthopaedics, General Hospital of Central Theater Command (Wuhan General Hospital of Guangzhou Command, previously), NO. 627, Wuluo Road, Wuhan 430030, Hubei Province, P. R. China. ${ }^{2}$ Department of Emergency, Taikang Tongji (Wuhan) Hospital, Wuhan, Hubei Province, P. R. China. ${ }^{3}$ Graduate School of Wuhan University of Science and Technology, Wuhan, Hubei Province, P. R. China. ${ }^{4}$ The First Clinical Medical School Of Southern Medical University, Guangzhou, Guangdong Province, P. R. China.

Received: 27 January 2021 Accepted: 21 March 2021

Published online: 30 March 2021

\section{References}

1. van Dijk CN, van Sterkenburg MN, Wiegerinck Jl, Karlsson J, Maffulli N. Terminology for Achilles tendon related disorders. Knee Surg Sports Traumatol Arthrosc. 2011;19(5):835-41. https://doi.org/10.1007/s00167-01 0-1374-z.

2. Chimenti RL, Cychosz CC, Hall MM, Phisitkul P. Current concepts review update: insertional Achilles tendinopathy. Foot Ankle Int. 2017;38(10):11609. https://doi.org/10.1177/1071100717723127.

3. Maffulli N, D'Addona A, Gougoulias N, Oliva F, Maffulli GD. Dorsally based closing wedge osteotomy of the calcaneus for insertional Achilles tendinopathy. Orthop J Sports Med. 2020;8(3):2325967120907985.

4. Giai Via A, Oliva F, Padulo J, Oliva G, Maffulli N. Insertional calcific tendinopathy of the Achilles tendon and dysmetabolic diseases: an epidemiological survey. Clin J Sport Med. 2020Publish Ahead of Print. https://doi.org/10.1097/JSM.0000000000000881.

5. Clain MR, Baxter DE. Achilles tendinitis. Foot Ankle. 1992;13(8):482-7 https://doi.org/10.1177/107110079201300810.

6. Fahlström M, Jonsson P, Lorentzon R, Alfredson H. Chronic Achilles tendon pain treated with eccentric calf-muscle training. Knee Surg Sports Traumatol Arthrosc. 2003;11(5):327-33. https://doi.org/10.1007/s00167-003-0418-z. 
7. Moher D, Liberati A, Tetzlaff J, Altman DG. Preferred reporting items for systematic reviews and meta-analyses: the PRISMA statement. BMJ (Clinical research ed). 2009;339:b2535.

8. Liberati A, Altman DG, Tetzlaff J, Mulrow C, Gøtzsche PC, loannidis JP, et al. The PRISMA statement for reporting systematic reviews and meta-analyses of studies that evaluate healthcare interventions: explanation and elaboration. BMJ (Clinical research ed). 2009;339:b2700

9. Wright JG, Swiontkowski MF, Heckman JD. Introducing levels of evidence to the journal. J Bone Joint Surg Am. 2003;85(1):1-3. https://doi.org/10.2106/ 00004623-200301000-00001.

10. Slim K, Nini E, Forestier D, Kwiatkowski F, Panis Y, Chipponi J. Methodological index for non-randomized studies (minors): development and validation of a new instrument. ANZ J Surg. 2003;73(9):712-6. https://doi.org/10.1046/j.1445-2197.2003.02748.x.

11. Ohberg L, Alfredson H. Sclerosing therapy in chronic Achilles tendon insertional pain-results of a pilot study. Knee Surg Sports Traumatol Arthrosc. 2003;11(5):339-43. https://doi.org/10.1007/s00167-003-0402-7.

12. Costantino C, Pogliacomi F, Vaienti E. Cryoultrasound therapy and tendonitis in athletes: a comparative evaluation versus laser $\mathrm{CO} 2$ and t.e.ca. R. therapy. Acta Bio-Medica Atenei Parmensis. 2005;76(1):37-41.

13. Furia JP. High-energy extracorporeal shock wave therapy as a treatment for insertional Achilles tendinopathy. Am J Sports Med. 2006;34(5):733-40. https://doi.org/10.1177/0363546505281810.

14. Knobloch K. Eccentric training in Achilles tendinopathy: is it harmful to tendon microcirculation? Br J Sports Med. 2007;41(6):e2 discussion e.

15. Rompe JD, Furia J, Maffulli N. Eccentric loading compared with shock wave treatment for chronic insertional achilles tendinopathy. A randomized, controlled trial. J Bone Joint Surg Am. 2008;90(1):52-61. https://doi.org/10.21 06/JBJS.F.01494.

16. Jonsson P, Alfredson $H$, Sunding K, Fahlström M, Cook J. New regimen for eccentric calf-muscle training in patients with chronic insertional Achilles tendinopathy: results of a pilot study. Br J Sports Med. 2008;42(9):746-9. https://doi.org/10.1136/bjsm.2007.039545.

17. Ryan M, Wong A, Taunton J. Favorable outcomes after sonographically guided intratendinous injection of hyperosmolar dextrose for chronic insertional and midportion achilles tendinosis. AJR Am J Roentgenol. 2010; 194(4):1047-53. https://doi.org/10.2214/AJR.09.3255.

18. Verrall G, Schofield S, Brustad T. Chronic Achilles tendinopathy treated with eccentric stretching program. Foot Ankle Int. 2011;32(9):843-9. https://doi. org/10.3113/FAl.2011.0843.

19. Saxena A, Ramdath S Jr, O'Halloran P, Gerdesmeyer L, Gollwitzer H. Extracorporeal pulsed-activated therapy ("EPAT" sound wave) for Achilles tendinopathy: a prospective study. J Foot Ankle Surg. 2011;50(3):315-9. https://doi.org/10.1053/j.jfas.2011.01.003.

20. Notarnicola A, Pesce V, Vicenti G, Tafuri S, Forcignanò M, Moretti B. SWAAT study: extracorporeal shock wave therapy and arginine supplementation and other nutraceuticals for insertional Achilles tendinopathy. Adv Ther. 2012;29(9):799-814. https://doi.org/10.1007/s12325-012-0046-4.

21. Notarnicola A, Maccagnano G, Tafuri S, Forcignanò Ml, Panella A, Moretti B. CHELT therapy in the treatment of chronic insertional Achilles tendinopathy. Lasers Med Sci. 2014;29(3):1217-25. https://doi.org/10.1007/s10103-013-1510-3.

22. Kedia M, Williams M, Jain L, Barron M, Bird N, Blackwell B, et al. The effects of conventional physical therapy and eccentric strengthening for insertional achilles tendinopathy. Int J Sports Phys Ther. 2014;9(4):488-97.

23. McCormack JR, Underwood FB, Slaven EJ, Cappaert TA. Eccentric exercise versus eccentric exercise and soft tissue treatment (Astym) in the management of insertional Achilles tendinopathy. Sports Health. 2016;8(3): 230-7. https://doi.org/10.1177/1941738116631498.

24. Taylor J, Dunkerley S, Silver D, Redfern A, Talbot N, Sharpe I, et al. Extracorporeal shockwave therapy (ESWT) for refractory Achilles tendinopathy: a prospective audit with 2-year follow up. Foot (Edinburgh, Scotland). 2016;26:23-9.

25. Pavone V, Cannavò L. Low-energy extracorporeal shock-wave therapy in the treatment of chronic insertional Achilles tendinopathy: a case series. Biomed Res Int. 2016;2016:7123769.

26. Wu Z, Yao W, Chen S, Li Y. Outcome of extracorporeal shock wave therapy for insertional Achilles tendinopathy with and without Haglund's deformity. Biomed Res Int. 2016;2016:6315846.

27. Erroi D, Sigona M, Suarez T, Trischitta D, Pavan A, Vulpiani MC, et al. Conservative treatment for insertional Achilles tendinopathy: platelet-rich plasma and focused shock waves. A retrospective study. Muscles Ligaments Tendons J. 2017;7(1):98-106. https://doi.org/10.11138/mltj/2017.7.1.098.

28. Maffulli G, Padulo J, Iuliano E, Furia J, Rompe J, Maffulli N. Extracorporeal shock wave therapy in the management of insertional Achilles tendinopathy the ASSERT database; 2018.

29. Wheeler PC. Extracorporeal shock wave therapy plus rehabilitation for insertional and noninsertional Achilles tendinopathy shows good results across a range of domains of function. J Foot Ankle Surg. 2019;58(4):617-22. https://doi.org/10.1053/j.jfas.2018.11.005.

30. Mansur NSB, Baumfeld T. Shockwave therapy associated with eccentric strengthening for Achilles insertional tendinopathy: a prospective study. Foot Ankle Spec. 2019;12(6):540-5.

31. Pinitkwamdee S, Laohajaroensombat S. Effectiveness of extracorporeal shockwave therapy in the treatment of chronic insertional Achilles tendinopathy. Foot Ankle Int. 2020;41(4):403-10.

32. Zhang S, Li H, Yao W, Hua Y, Li Y. Therapeutic response of extracorporeal shock wave therapy for insertional Achilles tendinopathy between sportsactive and nonsports-active patients with 5-year follow-up. Orthop J Sports Med. 2020;8(1):2325967119898118.

33. Alfredson $\mathrm{H}$, Pietilä $T$, Jonsson $P$, Lorentzon R. Heavy-load eccentric calf muscle training for the treatment of chronic Achilles tendinosis. Am J Sports Med. 1998:26(3):360-6. https://doi.org/10.1177/03635465980260030301.

34. Magnussen RA, Dunn WR, Thomson AB. Nonoperative treatment of midportion Achilles tendinopathy: a systematic review. Clin J Sport Med. 2009;19(1):54-64. https://doi.org/10.1097/JSM.0b013e31818ef090.

35. Sussmilch-Leitch SP, Collins NJ, Bialocerkowski AE, Warden SJ, Crossley KM Physical therapies for Achilles tendinopathy: systematic review and metaanalysis. J Foot Ankle Res. 2012;5(1):15. https://doi.org/10.1186/1757-11465-15.

36. van der Vlist AC, Winters M. Which treatment is most effective for patients with Achilles tendinopathy? A living systematic review with network metaanalysis of 29 randomised controlled trials; 2020.

37. Orhan Z, Ozturan K, Guven A, Cam K. The effect of extracorporeal shock waves on a rat model of injury to tendo Achillis. A histological and biomechanical study. J Bone Joint Surg. 2004;86(4):613-8.

38. Ohberg L, Lorentzon R, Alfredson H. Neovascularisation in Achilles tendons with painful tendinosis but not in normal tendons: an ultrasonographic investigation. Knee Surg Sports Traumatol Arthrosc. 2001;9(4):233-8. https://doi.org/10.1007/s001670000189.

39. Ohberg L, Alfredson H. Ultrasound guided sclerosis of neovessels in painful chronic Achilles tendinosis: pilot study of a new treatment. Br J Sports Med. 2002;36(3):173-5discussion 6-7. https://doi.org/10.1136/bjsm.36.3.173.

40. Cusi M, Saunders J, Hungerford B, Wisbey-Roth T, Lucas P, Wilson S. The use of prolotherapy in the sacroiliac joint. Br J Sports Med. 2010;44(2):100-4. https://doi.org/10.1136/bjsm.2007.042044.

41. Coombes BK, Bisset L, Vicenzino B. Efficacy and safety of corticosteroid injections and other injections for management of tendinopathy: a systematic review of randomised controlled trials. Lancet (London, England). 2010;376(9754):1751-67.

\section{Publisher's Note}

Springer Nature remains neutral with regard to jurisdictional claims in published maps and institutional affiliations.

Ready to submit your research? Choose BMC and benefit from:

- fast, convenient online submission

- thorough peer review by experienced researchers in your field

- rapid publication on acceptance

- support for research data, including large and complex data types

- gold Open Access which fosters wider collaboration and increased citations

- maximum visibility for your research: over $100 \mathrm{M}$ website views per year

At $\mathrm{BMC}$, research is always in progress.

Learn more biomedcentral.com/submissions 